\title{
KISALTILMIŞ İŞ-AİLE ZENGİNLEŞMESİ ÖLÇEĞİ TÜRKÇE FORMUNUN GEÇERLİK VE GÜVENİRLIKK ÇALIŞMASI
}

$* * * *$

\section{THE VALIDITY AND RELIABILITY STUDY OF THE TURKISH VERSION OF THE SHORTENED WORK-FAMILY ENRICHMENT SCALE}

\author{
Dr. Öğr. Üyesi Tahsin AKÇAKANAT \\ Süleyman Demirel Üniversitesi \\ İktisadi ve İdari Bilimler Fakültesi \\ İșletme Bölümü \\ tahsinakcakanat@sdu.edu.tr \\ ORCID: 0000-0001-9414-6868
}

Dr. Öğr. Üyesi Hasan Hüseyin UZUNBACAK Süleyman Demirel Üniversitesi İktisadi ve İdari Bilimler Fakültesi İşletme Bölümü hasanuzunbacak@sdu.edu.tr ORCID: 0000-0002-3297-1659

\section{Öz}

Bu araştırmanın amacı "Kısaltılmış Işs-Aile Zenginleşmesi Ölçeği'ni (Kacmar vd., 2014) Türkçeye uyarlamak ve geçerlik, güvenirlik analizlerini yapmaktır. Araştırmanın örneklemi, Antalya ilinde turizm sektöründe görev yapan 295 beyaz yakalı çalışandan oluşmaktadır. Yapılan açımlayıcı faktör analizi sonucunda toplam varyansın $\% 77,234$ 'ünü açıklayan, 6 madde ve 2 alt boyuttan oluşan bir ölçme aracı elde edilmiştir. Bu alt boyutlar Işs-Aile Zenginleşmesi ve Aile-İş Zenginleşmesi olarak isimlendirilmiştir. Ölçeğin faktör yükleri .79 ile 91 arasinda değişmektedir. Doğrulayıcı faktör analizi sonuçlarl, modelin mükemmel seviyede uyum verdiğini göstermiştir $\left(X^{2}=18,87, s d=8, R M S E A=.068, N F I=.98, N N F I=.98, C F I=.99, I F I=.99, R F I=.97, G F I=.98\right.$ ve AGFI= .95). İ̧̧ tutarlik güvenirlik katsayıları İş-Aile Zenginleşmesi için .88, Aile-İş̧ Zenginleşmesi için .81, olarak hesaplanmıştır. Madde analizi sonucunda alt ölçeklerin düzeltilmiş madde-toplam puan korelasyonlarının .63 ile .83 arasında değisştiği görülmüş̧ür. Bu bulgulara dayanarak, "Kısaltılmış İş-Aile Zenginleşmesi Ölçeği" örgütsel davranış alanında kullanılabilecek, Türk kültürüne uygun, geçerli ve güvenilir bir ölçme aracı olduğu anlaşılmıştır.

Anahtar Kelimeler: Kısaltılmış İş-Aile Zenginleşmesi Ölçeği, Geçerlilik, Güvenirlik.

\begin{abstract}
The purpose of this study is to adapt the Shortened Work-Family Enrichment Scale (Kacmar et al., 2014) to Turkish and to conduct validity and reliability analyzes. The sample of the study consists of 295 white-collar workers working in the tourism sector in Antalya. As a result of the explanatory factor analysis, a measuring instrument consisting of 6 items and 2 sub-dimensions explaining 77,234\% of the total variance was obtained. These sub-dimensions are called Work-Family Enrichment and Family-Work Enrichment. Factor loadings of the scale vary between .79 and .91. Confirmatory factor analysis results showed that the model was in perfect level $(X 2=18,87, s d=8, R M S E A=.068, N F I=.98, N N F I=.98, C F I=.99, I F I=.99, R F I=.97, G F I=.98$ and $A G F I=.95)$. Internal consistency reliability coefficients were calculated as .88 for Work-Family Enrichment and .81 for Family-Work Enrichment. As a result of the item analysis, it was seen that the corrected item-total score correlations of subscales changed between .63 and .83 . Based on these findings, it is understood that the Shortened Work-Family Enrichment Scale can be used in organizational behavior researchs and is a valid and reliable measurement tool suitable for Turkish culture.
\end{abstract}

Keywords: Shortened Work-Family Enrichment Scale, Validity, Reliability. 


\section{Gíriş}

Son yıllarda araştırmacılar tarafından, iş ve ailenin birbirleriyle olan ilişkisi ve etkisi üzerinde, çoğunluğu konuyu çatışma açısından ele alan çokça çalışma yapıldığı görülmektedir. Bununla birlikte, işgücünde kadınların çalışma yaşamında daha fazla yer almaya başlaması, ailede her iki eşinde çalışıyor olması gibi değişimler sebebiyle aile içerisindeki bireyler, aile ve iş ile ilgili daha fazla rol üstlenmek, iş ve aile yaşamında üstlendikleri her bir rolün sorumluluklarını doğru bir şekilde yerine getirmek ve yönetmek zorunda kalmaktadırlar. Bazı sosyoloji teorisyenleri, bu rollerin gereklerinin tam olarak yerine getirilmemesinin çatışmaya yol açabileceği düşüncesinin yanı sıra, çoklu rol üstlenmenin bireylere yarar sağlayan kaynakları da ortaya çıkarabileceğini öne sürmüşlerdir (Marks, 1977; Sieber, 1974). Nitekim, bu düşünceden hareketle, birçok araştırmacı tarafından iş-aile yaşamı ilişkisinin pozitif yayılma, kolaylaştırma, iyileştirme, zenginleşme gibi olumlu yönleri üzerinde çalışmalar yapılması gerektiği dile getirilmiştir (McNall, 2009: 62). Özellikle son yıllarda, pozitif bir bakış açından konuya yaklaşılarak çalışanların işte ve ailede üstlendikleri rollerin iş ve yaşam kalitesini nasıl etkilediğinin araştırıldığı görülmektedir. Bu araştırmaların odak noktasının, insan kaynağının geliştirilmesinin ve güçlenmesinin yeni yollarının aranması olduğu ifade edilmektedir (Siu vd., 2010: 470)

Buna yönelik ele alınan konulardan birisini de iş-aile zenginleşmesi kavramı oluşturmaktadır. İş-aile zenginleşmesi kavramı ilk olarak Greenhaus ve Powell'ın (2006) çalışmasında ele alınmıştır. Bu çalışmada iş aile zenginleşmesi, bireyin sahip olduğu bir rol gereğince edindiği deneyimin, sahip olduğu diğer roldeki yaşam kalitesini ve performansını artırması veya geliştirmesi olarak tanımlanarak, bu etkinin çift yönlü olduğu savunulmuştur. Bu çift yönlü etkiyi ise, işten elde ettiği deneyimlerin aile yaşam kalitesini artırması durumunda işten aileye doğru bir zenginleşme (İAZ), ailede elde ettiği deneyimlerin iş yaşam kalitesini artırması durumunda ise aileden işe doğru zenginleşmenin (AİZ) olacağı şeklinde açıklamışlardır (Greenhaus ve Powell, 2006: 73). Bu yazarlar ayrıca, bir rolde edinilen kaynakların, araçsal ve/veya duyuşsal yollarla diğer rolü zenginleştirebileceğini ileri sürmektedir. Araçsal zenginleşme, bir rolde kazanılan kaynaklar, diğer rolün performansında doğrudan etkili bir öneme sahip olduğunda ortaya çıkar. Bir rolde kazanılan kaynaklar olumlu bir etki yarattığında (bazen bu roldeki performansı artırdıkları için), diğer bir rolde performansı dolaylı olarak artıran duygusal zenginleşme olacaktır (Lapierre vd., 2017: 386).

Greenhaus ve Powell (2006), iş-aile zenginleşmesi ile ilgili geliştirdikleri modelde, zenginleşme sürecini belirleyen çeşitli kaynakların varlığından bahsetmişlerdir. Bunlar, beceri ve bakış açısı, psikolojik ve fiziksel kaynaklar, sosyal sermaye kaynakları, esneklik, maddi kaynaklar olmak üzere beş gruba ayrılmıştır (McNall vd., 2010: 383). Bu kaynaklardan birinin veya birden fazlasının bir rol gereğince elde edilmesinin, diğer rol için de olumlu yönde gelişmeye katkı sağlayacak kaynaklar haline geldiği savunulmaktadır (Carlson vd., 2006: 132).

$\mathrm{Bu}$ teorik bakış açısından sonra, Carlson ve arkadaşları iş-aile zenginleşmesini çeşitli alt boyutlarda ele alarak bir ölçek geliştirmişlerdir. Bu çalışmada iş- aile zenginleşmesi; bir rolde edinilen beceri ve bilgiye atıfta bulunarak, başka bir rolde entelektüel ve kişisel gelişimi ifade eden (1) $\dot{I} A Z$ Geliştirme ve (2) AIZZ-Geliştirme, bir başka rolden faydalanmak için kullanılan bir rol içindeki olumlu duygudurum ve tutumları ifade eden (3) $\dot{I} A Z$-Duygu ve (4) AIZZ-Duygu, işyerine katılımdan elde edilen ve ailede performansı artırmak için kullanılan kaynaklara (örneğin, başarı ve öz saygı gibi) atıfta bulunan (5) IAZ-Sermaye ve işyerinde performansı artırmak için kullanılabilecek aile sorumluluklarına dahil olmanın sağladığı faydaları ifade eden (6) AIZ-Verimlilik olmak üzere altı alt boyutta incelenmiştir (Carlson vd., 2006).

İş-aile zenginleşmesinin öncülleri ve sonuçları ile ilgili bazı meta-analiz çalışmaları yapılmıştır. İş-aile zenginleşmesinin öncülleri ile ilgili yapılan çalışmada, işten aileye zenginleşme boyutu ile işyerinde uygulanan sosyal destek, aile dostu politikalar ve kültür, kıdem, özerklik, katılım, adanmışlık ve iş odaklılık arasında pozitif, çalışma saatleri, aşırı iş yükü, iş güvencesizliği arasında negatif ilişkinin olduğu belirtilmiştir. Aileden işe zenginleşme boyutu ile aile desteği, medeni durum, aile etkinliklerine katılım ve aile odaklılık arasında pozitif, aileyle birlikte geçirilen zaman, aile sorumluluklarının fazlalığı, çocuk sayısı, küçük çocuk sahibi olma, eşin çalışma durumu, eşin çalışma 
saatleri arasında negatif ilişkinin olduğu ifade edilmiştir (Lapierre vd., 2017). İş-aile zenginleşmesinin sonuçları ile ilgili yapılan çalışmada ise, işten aileye zenginleşme düzeyinin iş tatmini, örgütsel bağlılık, işten ayrılma niyeti, tükenmişlik, örgütsel vatandaşlık davranışı, rol içi performans düzeyini etkilediği, aileden işe zenginleşme düzeyinin ise, aile tatmini ve aile performansını etkilediği belirtilmiştir. Her iki boyutun da sağlık durumu, yaşam tatmini ve stres üzerinde etkisi olduğu ifade edilmiştir. Cinsiyet, medeni durum, yaş, çocuk sayısı, ulusal kültür gibi değişkenlerin ise her iki boyutla sayılan öncüller ve sonuçlar arasında düzenleyici rolü olabileceği belirtilmiştir (McNall, 2010; Zhang vd., 2018).

Bu araştırmada, Kacmar ve arkadaşları (2014) tarafından geliştirilen "İş-Aile Zenginleşmesi Ölçeği Kısa Formu"nun Türkçeye uyarlaması ve Türkçe formunun geçerlilik ve güvenirlik analizinin yapılması amaçlanmıştır.

\section{YÖNTEM}

Bu başlık altında araştırmada kullanılan örneklem grubu, veri toplama aracı ve uyarlama çalışmasında izlenen süreçten bahsedilecektir.

\section{1. Çalışma Grubu}

Araştırmanın verileri Antalya ilinde, turizm sektöründe görev yapan 295 beyaz yakalı çalışandan elde edilmiştir. Örneklem büyüklüğü belirlenirken, ölçekte kullanılan madde sayısının 10 katı kadar deneğe ulaşmak önerilmektedir (Kline, 1994). Bu çalışmada ulaşılan örneklem sayısının bu bilgi 1şı̆̆ında yeterli olduğu düşünülmektedir. Katılımcıların 207'si (\%70,2) kadın, 88'i (\%29,8) erkektir.

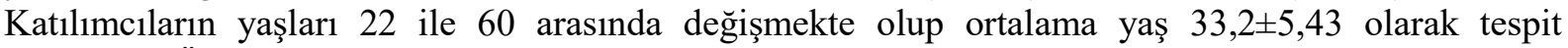
edilmiştir. Örneklemi oluşturan çalışanların 250'si $(\% 85,6)$ evli iken 45 kişi $(\% 14,4)$ ise bekârdır. Eğitim seviyesi açısından katılımcılar değerlendirildiğinde 61'i (\%20,7) önlisans 153’ü $(\% 51,9)$ lisans, 81 'i $(\% 27,5)$ ise lisansüstü bir programdan mezundur. Son olarak katılımcıların mesleki deneyim sürelerinin ortalaması ise $12,1 \pm 6,30$ olarak gerçekleşmiş̧ir.

\subsection{Veri Toplama Aracı}

$\mathrm{Bu}$ çalışmada, çalışanların iş-aile zenginleşmesi düzeylerini değerlendirmek amacıyla Carlson ve arkadaşları (2006) tarafından geliştirilen 18 maddelik İş-Aile Zenginleşmesi Ölçeği’nin (Work-Family Enrichment Scale), Kacmar ve arkadaşları (2014) tarafindan kısaltılan 6 maddelik şekli kullanılmıştır. İş-Aile Zenginleşmesi ve Aile-İş Zenginleşmesi şeklinde 2 alt boyuttan oluşan ölçekte ters puanlanmış madde bulunmamaktadır. Ölçek beşli likert (Kesinlikle Katılmıyorum için "1" ve Kesinlikle Katılıyorum için "5") olacak şekilde derecelendirilmiştir. Ölçekten alınan puanların yükselmesi, çalışanların iş-aile ya da aile-iş zenginleşme seviyelerinin arttığını göstermektedir. Açımlayıcı faktör analizi sonuçlarına göre, ölçeği oluşturan maddelerin faktör yükleri .75 ile .88 aralı̆̆ında değerler almıştır. Ölçeğin iç tutarlık katsayısı, iş-aile zenginleşmesi boyutu için .84 ve aile-iş zenginleşmesi boyutu için .80 olarak tespit edilmiştir.

\section{3. İşlem}

İş-Aile Zenginleşmesi Ölçeği Kısa Formunun Türkçeye uyarlanması çalışmasında ilk aşamada sorumlu yazar K. Michele Kacmar ile elektronik posta aracılığıyla iletişim kurularak uyarlama için izin istenmiştir. K. Michele Kacmar tarafından izin verildikten sonra (Ek-2) ölçeğin orijinal hali, İngilizceye hakim üç öğretim üyesi tarafından Türkçeye çevrilmiştir. Bir sonraki aşamada ise Türkçeye çevrilen formlar tekrar İngilizceye tercüme edilerek İngilizce formla arasındaki tutarlılığa bakılmıştır. Son olarak tutarlılığı onaylanan Türkçe form, hem anlam hem de dil bilgisi açısından değerlendirilerek gerekli düzenlemeler yapılmıştır. Oluşturulan bu form, uzmanlık alanı ölçme ve 
değerlendirme olan iki öğretim üyesi tarafından incelenmiş, anlaşılmayan veya birden çok anlam çıkarılabilecek olan ifadeler araştırılmış ve gerekli değişiklikler yapılmıştır. İş-Aile Zenginleşmesi Ölçeği Kısa Formunun geçerliliği, yapı geçerliliği incelenerek sınanmıştır. Yapı geçerliği, açımlayıcı (AFA) ve doğrulayıcı faktör analizi (DFA) birlikte kullanılarak araştırılmıştır. Ölçeğin güvenirliğini tespit etmek için iç tutarlık katsayısı yöntemi kullanılmış olup ayrıca düzeltilmiş madde-toplam korelasyonu incelenerek madde analizi yapılmıştır. Bahsedilen tüm bu işlemler için SPSS 22 ve LISREL 8.80 istatistik paket programlarından faydalanılmıştır.

\section{BULGULAR}

İş-Aile Zenginleşmesi Ölçeği Kısa Formunun Türkçeye uyarlama çalışmasında öncelikle madde analizi ve güvenilirlik başlıklarına yer verilecek olup ardından ölçeğin yapı geçerliliği ele alınacaktır.

\subsection{Madde Analizi}

Madde analizi, ölçekteki maddelerin ayırt etme gücünü tespit etmek için gerçekleştirilmiştir. Bu kapsamda ölçekteki maddelerin düzeltilmiş madde-toplam korelasyonları hesaplanmıştır. Her boyutun kendi toplam puanı kullanılarak, düzeltilmiş madde-toplam korelasyonları tespit edilmiştir. Düzeltilmiş madde-toplam korelasyonlarına ilişkin sonuçlar Tablo 1'de gösterilmiştir.

Tablo 1: İş-Aile Zenginleşmesi Ölçeği Kısa Formunun Düzeltilmiş Madde-Toplam Korelasyonları

\begin{tabular}{lcc}
\hline Boyut & $\begin{array}{c}\text { Madde } \\
\text { Numarası }\end{array}$ & $\begin{array}{c}\text { Düzeltilmiş Madde-Toplam } \\
\text { Korelasyonu }\end{array}$ \\
\hline \multirow{2}{*}{ İş-Aile } & 1 & .68 \\
Zenginleşmesi & 2 & .83 \\
& 3 & .79 \\
\hline \multirow{2}{*}{ Aile-İş } & 4 & .72 \\
Zenginleşmesi & 5 & .64 \\
& 6 & .63 \\
\hline
\end{tabular}

Tablo 1'de görüldüğg̈ üzere her iki boyutta da düzeltilmiş madde-toplam korelasyon puanları sırasıyla .68 ve .63'ün üzerindedir. Büyüköztürk (2003)'e göre, ölçek maddelerinin ayırt etme yeterliliğine sahip olabilmesi için düzeltilmiş madde-toplam puan korelasyonunun .30'un üzerinde olması gereklidir. Bu kapsamda, İş-Aile Zenginleşmesi Ölçeği Kısa Formu düzeltilmiş madde-toplam puan korelasyonlarının, yeterli seviyede olduğu Tablo 1'den anlaşılmaktadır.

\subsection{Güvenilirlik}

İş-Aile Zenginleşmesi Ölçeği Kısa Formunun güvenirlik çalışmaları kapsamında iç tutarlık güvenilirliği incelenmiştir. Ölçeğin iç tutarlılığını ölçmek amacıyla, boyutlar bazında iç tutarlılık katsayıları hesap edilmiş ve aşağıdaki tabloda sonuçlar verilmiştir. Tablo 2 'den de anlaşılacağ 1 üzere her iki boyutun da iç tutarlılık katsayısı kabul edilebilir en az güvenirlik katsayısı olan .70'in üzerindedir (Nunnally, 1978). Bu çalışmada elde edilen iç tutarlılık katsayıları, orijinal çalışmadakilerden (iş-aile zenginleşmesi için .84 ve aile-iş zenginleşmesi için .80) biraz daha yüksek seviyede gerçekleşmiştir. 
Tablo 2: İş-Aile Zenginleşmesi Ölçeği Kısa Formunun İç Tutarlık Yöntemiyle Hesaplanan Güvenirlik Katsayılar1

\begin{tabular}{lcc}
\hline Boyut & Madde Sayısı & İç Tutarlılık Katsayısı $(\boldsymbol{\alpha})$ \\
\hline İş-Aile Zenginleşmesi & 3 & .88 \\
\hline Aile-İş Zenginleşmesi & 3 & .81 \\
\hline
\end{tabular}

\subsection{Yapı Geçerliliği}

Bu çalışmada İş-Aile Zenginleşmesi Ölçeği Kısa Formunun geçerliliği, yapı geçerliliği bağlamında test edilmiştir. Bunun için öncelikle AFA sonrasında ise DFA uygulanmıştır. Çok sayıda ölçek uyarlama çalışmasında, AFA ve DFA'nın birlikte kullanıldığı tespit edilmiştir (Jöreskog ve Sörbom, 1993).

Verilen bilgiler 1şığında, AFA yapmak maksadıyla öncelikle verilerin faktörlenebilirliği Barlett Küresellik ve Kaiser-Meyer-Olkin (KMO) Örneklem Yeterliliği testleri ile araştırılmıştır. Çalışmada toplanan verilerin, faktör analizine uygun olup olmadığını anlamak için KMO değerine bakmak gerekir. KMO değerinin .60'dan fazla ve Barlett Küresellik testinin anlamlı sonuç vermesi durumunda veriler faktör analizi için uygundur (Büyüköztürk, 2003). Bu çalışmada yapılan analiz neticesinde KMO değeri .810 ve Barlett Küresellik testi sonucu $\left(\chi^{2}=954,333 ; p<.000\right)$ anlamlı olarak tespit edilmiştir. Ulaşılan bu bulgular neticesinde eldeki verilerin faktör analizine uygun olduğuna kanaat getirilmiştir.

İş-Aile Zenginleşmesi Ölçeği Kısa Formunun yapı geçerliliğini test etmek için gerçekleştirilen AFA'da temel bileşenler tekniği kullanılmıştır. Bu araştırmada eksen döndürmesi sırasında varimax tekniğinden faydalanılmıştır. Tablo 3'te AFA ile ulaşılan sonuçlara yer verilmiştir.

Gerçekleştirilen AFA neticesinde ölçeğin aynı orijinal formundaki gibi 2 boyuta ayrıldığ 1 tespit edilmiştir. Boyutlara orijinal ölçekte olduğu gibi "İş-Aile Zenginleşmesi" ve "Aile-İş Zenginleşmesi" isimleri verilmiştir. Nunnally (1978)'e göre madde faktör yüklerinin .50'nin üzerinde olması istenen bir durumdur. Ölçekteki tüm maddelerin faktör yük değerleri .50'nin üzerindedir. Bu sebeple ölçekteki maddelerin hiçbiri analiz dışı bırakılmamıştır. Özdeğeri 1'den büyük iki faktörden ilki olan iş-aile zenginleşmesi, varyansın \%40,416'sını açıklarken, aile-iş zenginleşmesi faktörünün varyansı açılama oranı \%36,818 olarak gerçekleşmiştir. İki faktör birlikte toplam varyansın \%77,234'ünü açıklamaktadır. Sonuç olarak AFA neticesinde ortaya çıkan yapının orijinal formdaki boyutlandırmayla bire bir örtüştüğü tespit edilmiştir.

Tablo 3: İş-Aile Zenginleşmesi Ölçeği Kısa Formunun AFA Sonuçları

\begin{tabular}{|c|c|c|}
\hline \multirow{2}{*}{ Madde No } & \multicolumn{2}{|c|}{ Döndürülmüş Faktör Yük Değerleri } \\
\hline & İş-Aile Zenginleşmesi & Aile-İş Zenginleşmesi \\
\hline 1. Madde & .79 & \\
\hline 2. Madde & .91 & \\
\hline 3. Madde & .87 & \\
\hline 4. Madde & & .82 \\
\hline 5. Madde & & .81 \\
\hline 6. Madde & & .81 \\
\hline Özdeğeri & 2,425 & 2,209 \\
\hline Açıklanan Varyans & 40,416 & 36,818 \\
\hline \multicolumn{2}{|l|}{ Toplam Açıklanan Varyans } & 77,234 \\
\hline $\mathrm{KMO}=$ & \multicolumn{2}{|c|}{$\chi 2=954,333(\mathrm{p}<.000)$} \\
\hline
\end{tabular}


İş-Aile Zenginleşmesi Ölçeği Kısa Formunun AFA ile belirlenen faktör yapısının, elde edilen verilerle ne derece uyum gösterdiğini tespit etmek amacıyla DFA uygulanmıştır (Şimşek, 2007: 4). Şekil 1'de DFA sonuçlarına yer verilmiştir.

Şekil 1: İş-Aile Zenginleşmesi Ölçeği Kısa Formuna İlişkin Yol Diyagramı ve Faktör Yükleri

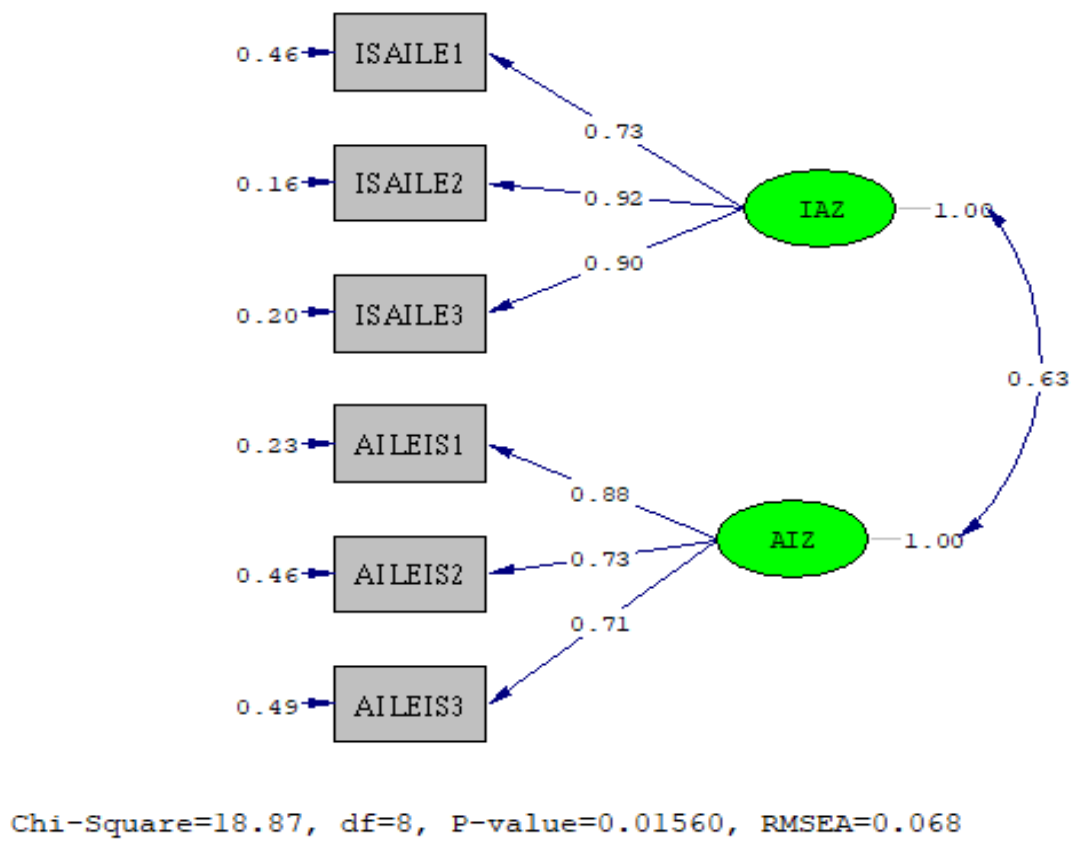

Şekil 1'de görüldüğü üzere LISREL programı kullanılarak yapılan birinci düzey DFA sonucunda ki-kare değeri anlamlıdır $\left(X^{2}=18,87, \quad s d=8, p=.015\right)$. Uyum iyiliği değerleri incelendiğinde $(\mathrm{RMSEA}=.068, \mathrm{NFI}=.98, \mathrm{NNFI}=.98, \mathrm{CFI}=.99, \mathrm{IFI}=.99, \mathrm{RFI}=.97, \mathrm{GFI}=.98$ ve $\mathrm{AGFI}=.95)$ ise ölçeğin 2 boyutlu model açısından mükemmel düzeyde uyum gösterdiği ve yap1 geçerliliğine sahip olduğu söylenebilir (Hu ve Bentler, 1999).

\section{SONUC VE ÖNERILER}

Bu çalışmada, Kacmar vd. (2014) tarafindan geliştirilen İş-Aile Zenginleşmesi Ölçeği Kısa Formunun, Antalya ilinde turizm sektöründe çalışan beyaz yakalılar için geçerliliği ve güvenilirliği araştırılmıştır. Ölçeğinin yapı geçerliliğini ortaya çıkarmak için AFA ve DFA uygulanmıştır. Ölçeğin güvenilirliğini tespit etmek amacıyla iç tutarlılık katsayıları incelenmiştir. Ayrıca her maddenin ayırt ediciliğini belirlemek maksadıyla madde analizi yapılmıştır. $\mathrm{Bu}$ işlemler neticesinde ulaşılan sonuçlar göstermektedir ki Türkçe form, orijinal formla birebir uyum göstermektedir (Ek-1).

Araştırma sadece bir ilde, turizm sektöründe çalışan beyaz yakalılar ile gerçekleştirildiği için sonuçların genellenebilmesi mümkün değildir. Araştırmacılar, ilerleyen zamanlarda ölçeğin uyum geçerliğini belirlemek maksadıyla, farklı değişkenlerle arasındaki ilişkiyi inceleyebilirler. Ayrıca, demografik değişkenlere yönelik farklılaşmaları ortaya çıkarmak amacıyla daha kapsamlı ve daha geniş örneklem kitleleriyle çalışmaların yapılması da yararlı olabilir.

Elde edilen bulgulara göre, ölçeğin Türk kültürüne uygun, kullanıma hazır, geçerli ve güvenilir bir ölçek olduğu söylenebilir. Ölçek, az sayıda madde içermesi, kolay ve hızlı bir şekilde uygulanabilmesi ve son olarak anlaşılır olması sebebiyle araştırmacılar tarafindan tercih edilecek bir ölçek olarak düşünülmektedir. 


\section{KAYNAKÇA}

BÜYÜKÖZTÜRK, Ş. (2003). Sosyal Bilimler İçin Veri Analizi El Kitabı (3. Baskı), Pegem Akademi Yayıncilık, Ankara.

CARLSON, D. S., KACMAR, K. M., WAYNE, J. H. ve GRZYWACZ, J. G. (2006). "Measuring The Positive Side of The Work-Family Interface: Development and Validation of a Work-Family Enrichment Scale", Journal of Vocational Behavior, 68(1): 131-164.

GREENHAUS, J. H. ve POWELL, G. N. (2006). "When Work and Family Are Allies: A Theory of Work-Family Enrichment", Academy of Management Review, 31(1): 72-92.

HU, L. T. ve BENTLER, P. M. (1999). "Cutoff Criteria for Fit Indexes in Covariance Structure Analysis: Conventional Criteria Versus New Alternatives", Structural Equation Modeling: A Multidisciplinary Journal, 6(1): 1-55.

JÖRESKOG, K. G. ve SÖRBOM, D. (1993). LISREL 8: Structural Equation Modeling with The SIMPLIS Command Language, Scientific Software International, Chicago, IL.

KACMAR, K. M., CRAWFORD, W. S., CARLSON, D. S., FERGUSON, M. ve WHITTEN, D. (2014). "A Short and Valid Measure of Work-Family Enrichment", Journal of Occupational Health Psychology, 19(1): 32-45.

KLINE, P. (1994). An Easy Guide to Factor Analysis, Routledge, New York.

LAPIERRE, L. M., LI, Y., KWAN, H. K., GREENHAUS, J. H., DIRENZO, M. S. ve SHAO, P. (2017). "A Meta-Analysis of The Antecedents of Work-Family Enrichment", Journal of Organizational Behavior, 39(4): 385-401.

MARKS, S. R. (1977). "Multiple Roles and Role Strain Some Notes on Human Energy Time and Commitment", American Sociological Review, 42(6): 921-936.

McNALL, L. A., MASUDA, A. D. ve NICKLIN, J. M. (2009). "Flexible Work Arrangements, Job Satisfaction, and Turnover Intentions: The Mediating Role of Work-To-Family Enrichment", The Journal of Psychology, 144(1): 61-81.

MCNALL, L. A., NICKLIN, J. M. ve MASUDA, A. D. (2010). “A Meta-Analytic Review of The Consequences Associated with Work-Family Enrichment", Journal of Business and Psychology, 25(3): 381-396.

NUNNALLY, J. C. (1978), Psychometric Theory (2. Baskı), McGraw-Hill, New York.

SIEBER, S. D. (1974). "Toward A Theory Of Role Accumulation", American Sociological Review, 39(4): 567-578.

SIU, O. L., LU, J. F., BROUGH, P., LU, C. Q., BAKKER, A. B., KALLIATH, T. ... ve KAN, S. (2010). "Role Resources and Work-Family Enrichment: The Role of Work Engagement", Journal of Vocational Behavior, 77(3): 470-480.

ŞİMŞEK, Ö. F. (2007). Yapısal Eşitlik Modellemesine Giriş Temel İlkeler ve Lisrel Uygulamaları, Ekinoks Eğitim Yayıncılık, Ankara.

ZHANG, Y., XU, S., JIN, J. ve FORD, M. T. (2018). "The Within and Cross Domain Effects of Work-Family Enrichment: A Meta-Analysis", Journal of Vocational Behavior, 104: 210-227. 
Ek-1: İş-Aile Zenginleşmesi Ölçeği Kısa Formu

\begin{tabular}{|c|c|c|c|c|c|}
\hline $\begin{array}{l}\text { Lütfen aşağıdaki ifadeleri okuduktan sonra kendinizi değerlendirip sizin } \\
\text { için en uygun seçeneğin karşısına çarpı }(\mathrm{X}) \text { işareti koyunuz. }\end{array}$ & 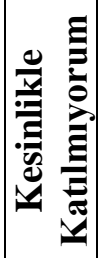 & 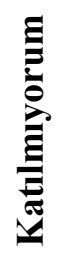 & 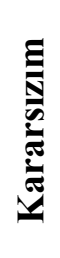 & E & 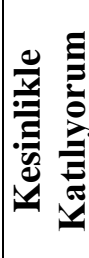 \\
\hline $\begin{array}{l}\text { Yaptığım iş, farklı bakış açılarını anlamama yardımcı olur, bu da benim } \\
\text { daha iyi bir aile üyesi olabilmemi sağlar. }\end{array}$ & 1 & 2 & 3 & 4 & 5 \\
\hline $\begin{array}{l}\text { Yaptığım iş, kendimi mutlu hissetmemi sağlar, bu da benim daha iyi bir } \\
\text { aile üyesi olabilmeme yardımcı olur. }\end{array}$ & 1 & 2 & 3 & 4 & 5 \\
\hline $\begin{array}{l}\text { Yaptığım iş, kişisel olarak tatmin olmama yardımcı olur, bu da benim } \\
\text { daha iyi bir aile üyesi olabilmemi sağlar. }\end{array}$ & 1 & 2 & 3 & 4 & 5 \\
\hline $\begin{array}{l}\text { Ailem, bana yetenek kazanmam konusunda yardımcı olur, bu da benim } \\
\text { daha iyi bir çalışan olmamı sağlar. }\end{array}$ & 1 & 2 & 3 & 4 & 5 \\
\hline $\begin{array}{l}\text { Ailem, benim iyi bir ruh halinde olmamı sağlar, bu da benim daha iyi bir } \\
\text { çalıșan olmama yardımcı olur. }\end{array}$ & 1 & 2 & 3 & 4 & 5 \\
\hline $\begin{array}{l}\text { Ailem, çalışma saatim boyuncu işime odaklanmam konusunda bana } \\
\text { ögütte bulunur, bu da benim daha iyi bir çalıșan olmama yardımcı olur. }\end{array}$ & 1 & 2 & 3 & 4 & 5 \\
\hline
\end{tabular}

Ek-2: Ölçek Uyarlaması İzni İçin Yapılan Yazışmalar

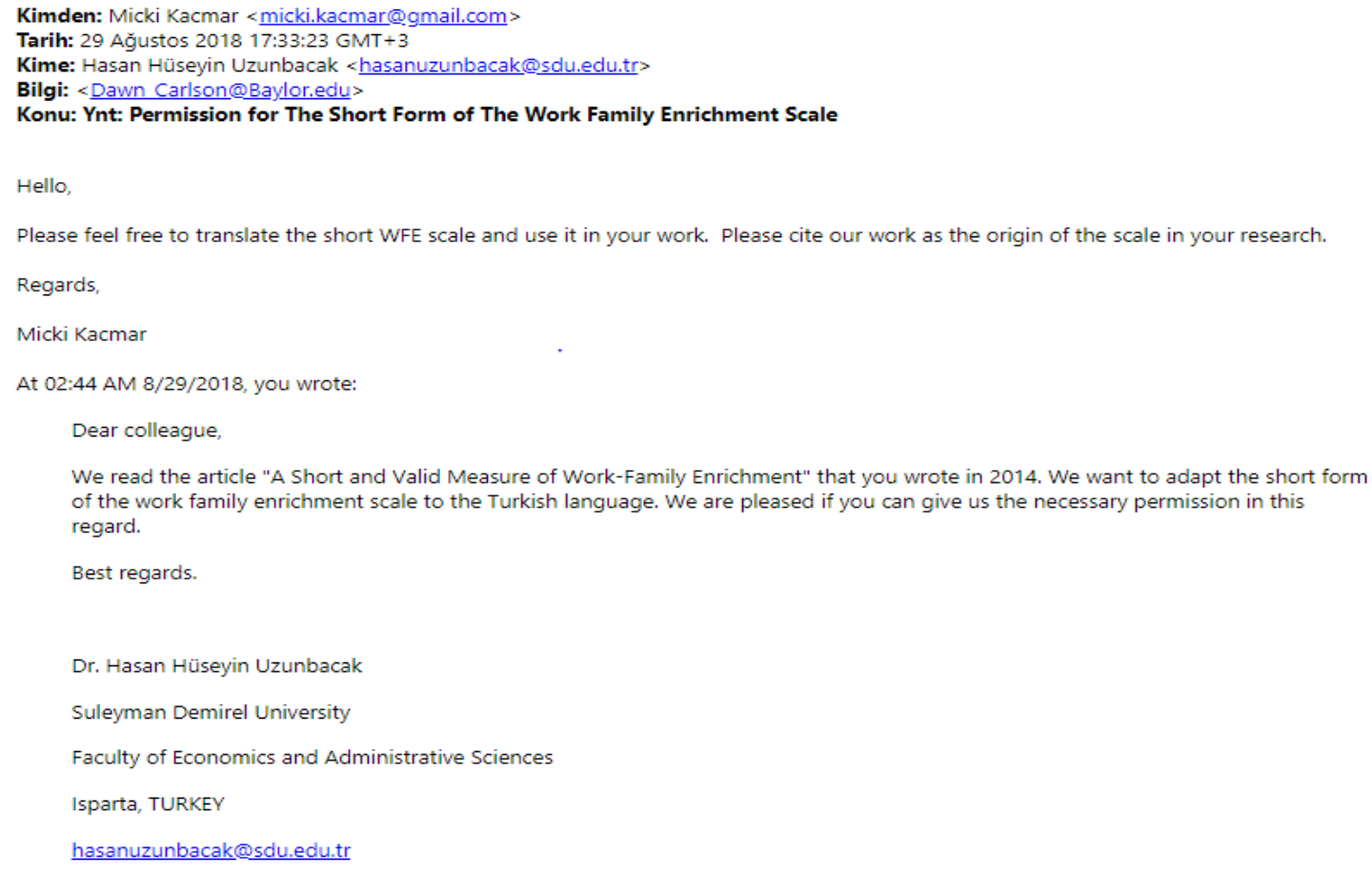

